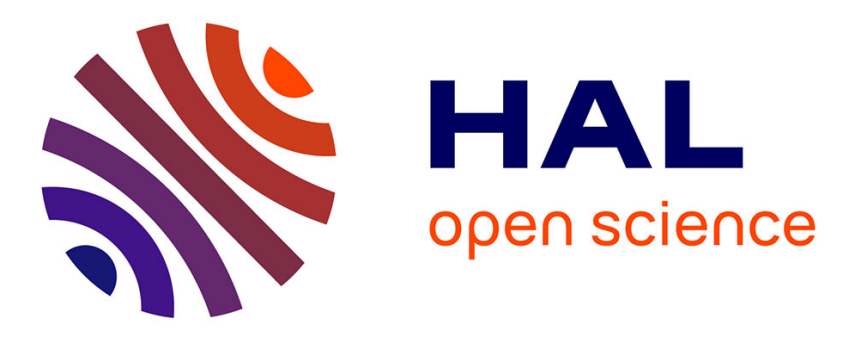

\title{
Presence of low-grade inflammation in old rats does not worsen skeletal muscle loss under an endotoxemic and dietary stress
}

Gilles Mayot, Karine Vidal, Lydie Combaret, Denis Breuillé, Stephanie Blum, Christiane Obled, Isabelle Papet

\section{To cite this version:}

Gilles Mayot, Karine Vidal, Lydie Combaret, Denis Breuillé, Stephanie Blum, et al.. Presence of low-grade inflammation in old rats does not worsen skeletal muscle loss under an endotoxemic and dietary stress. Experimental Gerontology, 2007, 42 (12), pp.1167. 10.1016/j.exger.2007.09.002 . hal00499029

\section{HAL Id: hal-00499029 \\ https://hal.science/hal-00499029}

Submitted on 9 Jul 2010

HAL is a multi-disciplinary open access archive for the deposit and dissemination of scientific research documents, whether they are published or not. The documents may come from teaching and research institutions in France or abroad, or from public or private research centers.
L'archive ouverte pluridisciplinaire HAL, est destinée au dépôt et à la diffusion de documents scientifiques de niveau recherche, publiés ou non, émanant des établissements d'enseignement et de recherche français ou étrangers, des laboratoires publics ou privés. 


\section{Accepted Manuscript}

Presence of low-grade inflammation in old rats does not worsen skeletal muscle loss under an endotoxemic and dietary stress

Gilles Mayot, Karine Vidal, Lydie Combaret, Denis Breuillé, Stephanie Blum, Christiane Obled, Isabelle Papet

PII:

S0531-5565(07)00214-8

DOI:

10.1016/j.exger.2007.09.002

Reference:

EXG 8384

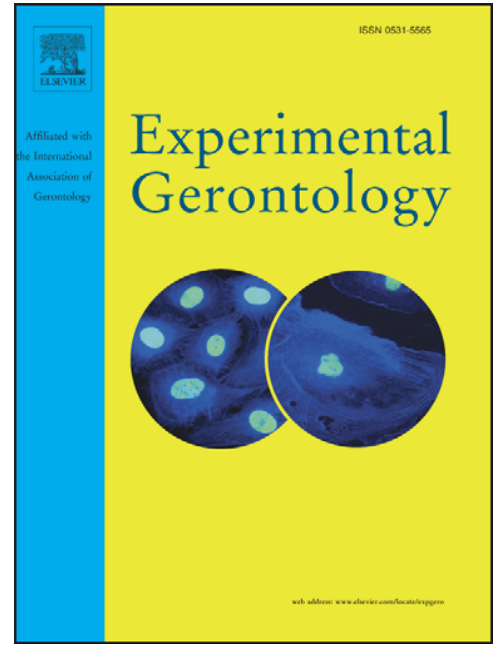

To appear in:

Experimental Gerontology

Received Date:

3 May 2007

Revised Date:

8 August 2007

Accepted Date:

14 September 2007

Please cite this article as: Mayot, G., Vidal, K., Combaret, L., Breuillé, D., Blum, S., Obled, C., Papet, I., Presence of low-grade inflammation in old rats does not worsen skeletal muscle loss under an endotoxemic and dietary stress, Experimental Gerontology (2007), doi: 10.1016/j.exger.2007.09.002

This is a PDF file of an unedited manuscript that has been accepted for publication. As a service to our customers we are providing this early version of the manuscript. The manuscript will undergo copyediting, typesetting, and review of the resulting proof before it is published in its final form. Please note that during the production process errors may be discovered which could affect the content, and all legal disclaimers that apply to the journal pertain. 
1 Presence of low-grade inflammation in old rats does not worsen skeletal muscle

2 loss under an endotoxemic and dietary stress

3

4 Gilles Mayot ${ }^{\mathrm{a}}$, Karine Vidal ${ }^{\mathrm{b}}$, Lydie Combaret ${ }^{\mathrm{a}}$, Denis Breuillé ${ }^{\mathrm{b}}$, Stephanie Blum ${ }^{\mathrm{b}}$, 5 Christiane Obled ${ }^{\text {a }}$, Isabelle Papet ${ }^{\mathrm{a}}{ }^{*}$

6

7 a INRA, Centre Clermont-Ferrand - Theix, UMR 1019 Unité de Nutrition Humaine, F-63122

8 Saint-Genès-Champanelle, France

9 butrition and Health Department, Nestlé Research Center, 1000 Lausanne 26, Switzerland 10

$11 *$ To whom correspondence should be addressed: Dr. Isabelle Papet, Unité de Nutrition 12 Humaine, INRA Theix, 63122 Saint-Genès-Champanelle, France.

13 Telephone: 33473624201

14 Fax: 33473624755

15 Email: papet@clermont.inra.fr

16

17 Running title: Response to a stress in inflamed or not old rats

Keywords: Ageing; Inflammation; Lipopolysaccharide; $\alpha_{2}$-macroglobulin; Fibrinogen;

20 Albumin.

21

22 Abbreviations used: CRP: C-reactive protein, BW: body weight, EDL: extensor digitorum

23 longus, IL-6: interleukin-6, LGI-Con: low-grade inflamed rats submitted to the control 24 treatment, LGI-Str: low-grade inflamed rats submitted to the stress, NI-Con: non-inflamed 
25 rats submitted to the control treatment, NI-Str: non-inflamed rats submitted to the stress,

26 TNF- $\alpha$ : tumor necrosis factor-alpha. 


\section{Abstract}

28 The study aimed to determine if age-associated low-grade inflammation aggravates the 29 response to a stress, especially regarding to sarcopenia. Initial inflammatory status in 22 30 month-old rats was based on plasma $\alpha_{2}$-macroglobulin and fibrinogen concentrations. The 31 stress applied was a single intra-peritoneal injection of lipopolysaccharide followed by a 2332 day period of malnutrition, i.e. a $4 \%$ casein diet distributed in quantity limited to $50 \%$ of 33 spontaneous food intake. The response to the stress was analyzed in non-inflamed and low34 grade inflamed rats and compared to non-inflamed and low-grade inflamed rats, which received the control treatment (i.e. no lipopolysaccharide injection and an $18 \%$ casein diet).

36 The stress-induced body weight loss was higher in inflamed than non-inflamed rats, but the 37 decrease in muscle weight was not worsened. Muscle protein turnover was not affected by the 38 stress. Plasma $\alpha_{2}$-macroglobulin levels increased after the stress, whatever the initial inflammatory status. However, fibrinogen levels decreased more in inflamed than noninflamed rats and albumin levels were not affected by the stress. Independently of the initial

41 inflammatory status, the liver glutathione content was strongly depleted by the stress. These

42 results extend and support our previous findings by demonstrating that age-associated low43 grade inflammation does not aggravate sarcopenia in old rats. 


\section{Introduction}

Frailty syndrome is an age-associated physiological state of vulnerability, resulting from impaired homeostatic reserves and a reduced capacity to withstand stress (Fried and Walston, 2003). Frailty consists of multi-system decline and is considered to be a consequence of changes in neuromuscular, endocrine and immune functions that occur as people progress in age (Fried and Walston, 2003; Vanitallie, 2003; Ferrucci et al., 2005; Paganelli et al., 2006). Frailty often results in several "vicious loops": neuromuscular impairment induces increased rate of falls and fractures in old age; the act of falling causes itself hospitalization and immobilization, which aggravates sarcopenia; sarcopenia leads to deficit in continuous neuromuscular training which brings about neuromuscular impairment (Bales and Ritchie, 2002; Fried and Walston, 2003; Mühlberg and Sieber, 2004). The unintentional body weight loss, which is a frailty criterion (Fried et al., 2001), usually results from poor responses to successive various stresses (Vellas et al., 1992).

Frail subjects exhibit evidence of increased inflammation revealed by modified acute phase protein concentrations (Walston et al., 2002; Puts et al., 2005). Age-associated increase in the levels of inflammatory markers, such as interleukin-6 (IL-6) and CRP, are associated with disability and mortality (Ferrucci et al., 1999; Harris et al., 1999; Ferrucci et al., 2002;

Cohen et al., 2003). Since age-associated inflammation appears to be an important component of frailty (De Martinis et al., 2006), it could worsen the aged subjects' response to a stress. $\underline{\text { In }}$ the same way, acute phase proteins, such as $\alpha_{2}$-macroglobulin and fibrinogen have been recently identified as markers of frailty in old rats (Mayot et al., 2007).

$\underline{\text { CRP, IL-6 and tumor necrosis factor- } \alpha \text { (TNF- } \alpha \text { ) receptor-2 levels were negatively }}$ correlated with the rate of skeletal muscle protein synthesis (Toth et al., 2005). Similarly, in $\underline{\text { frail human skeletal muscle, TNF- } \alpha \text { mRNA and protein levels decreased in concert with }}$ increases in strength and protein synthesis after 3 months of resistance exercise (Greiwe et al., 
2001). These results support the idea that age-associated low-grade inflammation affects

skeletal muscle metabolism and could participate in sarcopenia development. However, they do not prove the causal relationship within the old population. Indeed, inflamed/frail subjects are often older than control groups (Walston et al., 2002; Barbieri et al., 2003). Thus, these observations may be independent of inflammatory status and more directly related to age. Indeed we observed that low-grade inflammation, lasting at least one month, does not enhance sarcopenia in old rats (Mayot et al., 2006). Since this investigation was performed in rats kept in conditions minimizing any kind of stress, it is not excluded that age-associated low-grade inflammation could impact the old rats' response to a stress.

Diseases, such as infections, and periods of malnutrition, which are frequent in elderly patients, are stressor events that may accelerate frailty (Fried and Walston, 2003). Sarcopenia is associated with a doubled risk of nosocomial infection (Cosqueric et al., 2006). Poor daily energy intake and protein intake adjusted for energy intake are related to frailty (Bartali et al., 2006). Four to $31 \%$ of free-living and up to $60 \%$ of geriatrics patients on admission in hospitals or nursing homes have shown evidence of malnutrition (Seiler, 2001). Most of these deficits affecting ill elderly subjects are related to proteins and micronutrients. An low protein $\operatorname{diet}(0.45$ vs. $0.92 \mathrm{~g} / \mathrm{kg} / \mathrm{d})$ reduced muscle mass and function in elderly women (Castaneda et al., 1995). Acute diseases and malnutrition decrease skeletal muscle mass, which provides amino acids for most vital functions (Heymsfield et al., 1982; Obled et al., 2002).

The aim of the present study was to evaluate whether age-associated low-grade inflammation impacts the old rats' response to a stress. The chosen stress combines a shortlasting inflammation (endotoxin injection) and protein-energy malnutrition. This double stress was used to mimic a situation in elderly subjects, who frequently face any kind of transient febrile episode followed by a period of protein-energy malnutrition. The investigation was primarily focused on body weight change, skeletal muscle weight and protein metabolism. 
94 The acute phase protein response, weights of various organs and the glutathione liver status

95 were considered as complementary targets.

96

\section{Material and methods}

\subsection{Animals}

Wistar male rats were produced and bred in our conventional, non specific-pathogen-

100 free, animal facility (Unité Expérimentale de Nutrition Comparée, INRA, Theix, France).

101 Before the experiment, rats were maintained in collective cages ( 3 to 4 per cage) under

102 controlled conditions (temperature $21^{\circ} \mathrm{C}$, relative humidity $55 \%, 12-\mathrm{h}$ dark period starting at $1032000 \mathrm{~h}$ ). They had free access to water and standard pellets (A04 from SAFE (Scientific

104 Animal Food and Engineering), Villemoisson-sur-orge, France). The composition of the diet 105 was $16 \%$ protein, $3 \%$ fat, $60 \%$ carbohydrates, $12 \%$ water, fibers, vitamins and minerals. The 106 study was performed according to the current legislation on animal experiments in France.

\subsection{Experimental design}

109 2.2.1. Pre-experimental period

110 At the age of 22 months, rats which were apparently ill and those exhibiting acute

111 phase proteins levels that are predictive of old rat mortality (Mayot et al., 2007) [i.e. $\alpha_{2^{-}}$

112 macroglobulin and fibrinogen concentrations higher than $500 \mathrm{mg} / \mathrm{l}$ and $5.4 \mathrm{~g} / \mathrm{l}$, respectively]

113 were excluded. Thirty-four apparently healthy rats were housed in individual cages and

114 acclimatized to their new environment for 3 weeks. They received a diet containing $18 \%$

115 casein over 4 daily periods of 3 hours each, regularly spaced. The quantity of food distributed

116 during the light and dark periods were adjusted to represent about 30 and $70 \%$ of the $\mathrm{ad}$

117 libitum daily intake, respectively. Four rats died during this period and two rats, which did not 
118 eat, were excluded. Blood was withdrawn from a lateral tail vein 7 days before the end of the

119 pre-experimental period.

$120 \quad$ 2.2.2. Main experiment

121 Rats were distributed into 2 classes (non-inflamed (NI) and low-grade inflamed (LGI),

$122 \mathrm{n}=14$, each) based on their inflammatory status that was analyzed by hierarchical clustering

123 using Ward distance on $\alpha_{2}$-macroglobulin and fibrinogen variables (Mayot et al., 2007). At

124 day 0, each class was sub-divided into two groups receiving either the control $\underline{(\mathrm{Con})}$ or the

125 stress $\underline{(\mathrm{Str})}$ treatment. The control treatment, consisting in maintaining rats in the pre-

126 experimental conditions, was applied to 6 non-inflamed rats (NI-Con group) and 5 low-grade

127 inflamed rats ( $\underline{\text { LGI-Con }}$ group). The stress consisted in a single intra-peritoneal injection of

128 lipopolysaccharide from Escherichia coli 0127:B8 (0.4 mg/kg) followed by a 23-day period

129 of protein-energy malnutrition, during which rats received a diet containing $4 \%$ casein in

130 quantity individually limited to $50 \%$ of spontaneous food intake (distributed in four meals as

131 for control treatment). It was applied to 8 non-inflamed rats (NI-Str group) and 9 low-grade

132 inflamed rats (LGI-Str group). Rats were weighed at day 0 then three times per week. Blood

133 was sampled at day 8 at day 21 for plasma analyses. At day 23, all surviving rats $(\mathrm{n}=5$ for

134 NI-Con, LGI-Con and NI-Str groups and $\mathrm{n}=7$ for LGI-Str group) were anaesthetized with an

135 intra-peritoneal injection of ketamine $(150 \mathrm{mg} / \mathrm{kg})$. Epitrochlearis muscle was quickly

136 removed and incubated to measure in vitro protein metabolism, as already described

137 (Combaret et al., 2003). Rats were then killed by aortic blood withdraw. Posterior leg skeletal

138 muscles, liver, spleen, kidneys, epidydimal adipose tissue, mesentery, small intestine, colon

139 were dissected and weighted. Liver was frozen at $-80{ }^{\circ} \mathrm{C}$ until glutathione analysis.

\section{$140 \quad$ 2.3. Biochemical measurements}

$141 \quad$ Plasma $\alpha_{2}$-macroglobulin, fibrinogen and albumin were measured as already described

142 (Mayot et al., 2007). Total glutathione was quantified spectrophotometrically using a standard 
143 enzymatic recycling procedure and 5,5'-dithio-bis-2-nitrobenzoic acid as oxidant (Malmezat

144 et al., 1998).

145 2.4. Statistical analysis

146 Values are given as means \pm SE. The significance of difference between non-inflamed

147 and low-grade inflamed rats during the pre-experimental period was analyzed with Student's t

148 test for unpaired data. The significance of the initial inflammatory status and the treatment

149 effects was analyzed with 2-way ANOVA. For parameters measured before and at various

150 times after stress induction ANOVA for repeated measurements was performed with the

151 initial inflammatory status and the treatment as the between-rat factors and the time as the

152 within-rat factor. The significance of differences among the four groups was further analyzed

153 by Fisher's PLSD test, when appropriate. Linear regression was used to determine the

154 relationship between acute phase protein variation and body weight change. $P$ values $\leq 0.05$

155 were considered significant. Statistical analyses were performed using StatView for

156 Windows, version 5 software (SAS Institute, Cary, NC), excepted the hierarchical clustering

157 using Ward distance, which was performed with XLSTAT, version 7.5 software (Addinsoft,

158 Paris, France).

159

160 3. Results

161 3.1. Old rats' characteristics before the experimental period

162 According to the experimental design, low-grade inflamed rats exhibited 287 and $41 \%$

163 higher initial plasma concentrations of $\alpha_{2}$-macroglobulin $(147 \pm 21$ vs. $38 \pm 6 \mathrm{mg} / \mathrm{l}, P=$

$164 \underline{0.0002)}$ and fibrinogen $\underline{(4.5 \pm 0.2 \text { vs. } 3.2 \pm 0.1 \mathrm{~g} / \mathrm{l}, P=0.0002)}$, respectively (Table 1$)$. As

165 expected, low-grade inflamed rats exhibited $13 \%$ lower initial concentration of albumin than

166 non-inflamed rats $\underline{(12.1 \pm 0.6 \text { vs. } 13.9 \pm 0.6 \mathrm{~g} / \mathrm{l}, P=0.055)}$; however this difference was only

167 a trend. Maximal initial concentrations of $\alpha_{2}$-macroglobulin and fibrinogen were $307 \mathrm{mg} / 1$ 
168

169

170

171

172

173

174

175

176

177

178

179

180

181

182

183

184

185

186

187

188

190

191

192

and $5.6 \mathrm{~g} / \mathrm{l}$, respectively, and minimal initial concentration of albumin was $8.3 \mathrm{~g} / \mathrm{l}$. The relative body weight loss occurring over the pre-experimental period (day -22 to day 0 ) was $74 \%$ higher in low-grade inflamed than non-inflamed rats $\underline{(-6.7 \pm 1.3 \text { vs. }-3.9 \pm 1.2 \%, P=}$ $\underline{0.134)}$ without change in food intake; however the effect of the initial inflammatory status did not attain statistical significance. Based on 2-way ANOVA, groups did not differ with respect to mean body weights at days -22 and 0 , and food intake before day 0 (Table 1 ). No interaction between treatment and initial inflammatory status was significant for any measured parameter (Table 1) indicating the absence of any bias related to the configuration of the groups.

3.2. Stress-induced mortality and body weight change in low-grade inflamed and noninflamed old rats

The stress (endotoxin injection followed by protein-energy malnutrition) applied to the old rats induced 37 and 22\% of mortality in NI-Str and LGI-Str groups, respectively. Indeed, three rats from $\underline{\text { NI-Str }}$ group deceased at days 1,2, and 6 and two rats from LGI-Str group deceased at days 1 and 22. No mortality was observed in non-stressed rats, but one rat from

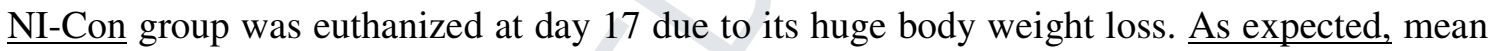
relative body weight losses (\%) over 23 days were very much higher in stress groups (NI-Str: $21.0 \pm 1.0$ and LGI-Str: $24.0 \pm 1.3$ ) than in control groups (I-Con: $2.2 \pm 0.6$ and LGI-Con: $2.2 \pm 1.4$ ). Based on the ANOVA for repeated measurements, cumulative body weight loss was dependent on the treatment and the time but not on the initial inflammatory status of rats (Fig. 1). The significant interaction between the treatment, the initial inflammatory status and the time likely reflects the fact that relative body weight losses over time were higher in LGI$\underline{\text { Str }}$ than NI-Str, whereas they were similar in NI-Con and LGI-Con groups. Comparison of results from $\underline{\text { LGI-Str }}$ and $\underline{\text { LGI-Con }}$ groups with the ANOVA for repeated measurements indicated that the relative body weight losses over time was higher in LGI-Str than in NI-Str 
193 (there was a significant interaction between the initial inflammatory status and time). It is

194 worthwhile to note that stress-induced body weight loss (I-Str and LGI-Str groups) was

195 correlated with initial concentration of either $\alpha_{2}$-macroglobulin $\left(\mathrm{r}^{2}=0.545, P=0.006\right)$ or

196 fibrinogen $\left(\mathrm{r}^{2}=0.331, P=0.050\right)$ and inversely correlated with the initial albumin

197 concentration $\left(\mathrm{r}^{2}=0.340, P=0.047\right)$.

198 3.3. Stress effects on skeletal muscles in low-grade inflamed and non-inflamed old rats

199 Based on two-way ANOVA, the stress (endotoxin injection followed by protein200 energy malnutrition) applied to the old rats decreased absolute and relative gastrocnemius 201 muscle weights by $12 \% \underline{(2.02 \pm 0.07 \text { vs. } 2.31 \pm 0.06 \mathrm{~g})}$ and $15 \% \underline{(323 \pm 11 \text { vs. } 379 \pm 17}$

$202 \mathrm{mg} / 100 \mathrm{~g}$ body weight at day $0(\mathrm{BW})$ ), respectively (Table 2). The same trend was observed 203 for the absolute and relative weight of tibialis anterior ( $-9 \%(744 \pm 26$ vs. $815 \pm 24 \mathrm{~g})$ and $20411 \%(119 \pm 5$ vs. $134 \pm 5 \mathrm{mg} / 100 \mathrm{~g} \mathrm{BW}))$. The stress had no effect on entensor digitorum 205 longus (EDL) and soleus. The initial inflammatory status did not affect the muscle weights, 206 excepted for the relative weight of soleus, which was $18 \%$ higher in inflamed $\underline{(30.1 \pm 0.8}$

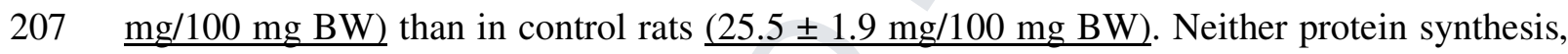
208 nor protein degradation was affected by the treatment or the initial inflammatory status (Fig. $2092)$.

210 3.4. Stress effects on organs and adipose tissues in low-grade inflamed and non-inflamed old 211 rats

212 The stress (endotoxin injection followed by protein-energy malnutrition) applied to 213 old rats decreased absolute (and relative) weights of spleen, liver, kidneys and small intestine 214 by about 33 (34), 27 (28), 26 (28) and 10\% (12\%), respectively (Table 3). The significance 215 was not reached for the stress-induced decreases in absolute and relative weights of colon, 216 mesentery and epidydimal adipose tissue respectively. Inflamed rats exhibited higher absolute 217 (42\%) and relative (48\%) weights of kidneys and 11\% higher relative weight of liver than 
218 non-inflamed rats. Interaction between stress and initial inflammatory status was significant

219 for absolute weight of kidneys and relative weights of kidneys and liver, indicating that stress-

220 induced decreases in these organ weights were higher in inflamed than non-inflamed rats. The

221 initial inflammatory status had no significant effect on absolute or relative weights of colon,

222 mesentery and epidydimal adipose tissue.

223 3.5. Stress effects on acute phase proteins and liver glutathione in low-grade inflamed and 224 non-inflamed old rats

225 The stress, the initial inflammatory status and the time had significant effects on both 226 $\alpha_{2}$-macroglobulin and fibrinogen plasma concentrations (Fig. 3), and the interaction between the stress and the time was significant for fibrinogen. Only initial inflammatory status had a significant effect on albumin plasma concentration. As expected, $\alpha_{2}$-macroglobulin, fibrinogen and albumin were stable over time in non-stressed rats (NI-Con and $\underline{\text { LGI-Con }}$ groups). In stressed rats (I-Str and LGI-Str groups), $\alpha_{2}$-macroglobulin was higher at days 8

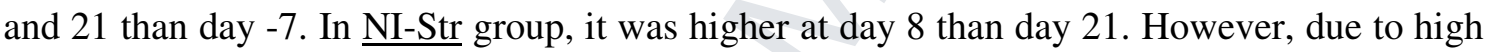
variability, differences were not significant in LGI-Str group. The decrease in fibrinogen at days 8 and 21 was higher in LGI-Str than NI-Str group to reach similar values as in $\underline{\text { NI-Con }}$ group. Albumin was stable in stressed rats.

The stress, but not the initial inflammatory status, had a significant effect on glutathione status (Fig. 4). Glutathione concentration and content were 59\% (3.04 \pm 0.6 vs.

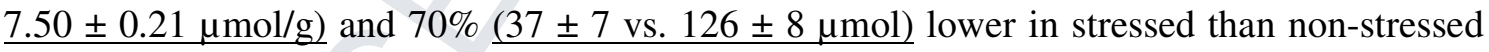
rats, respectively.

\section{Discussion}

The present data indicate that age-associated low-grade inflammation renders old rats 
243 skeletal muscle weight. Stress-induced decreases in some abdominal organ weights and in

244 fibrinogen plasma concentrations were enhanced by the initial low-grade inflammatory status,

245 but responses of the other acute phase proteins to the stress and stress-induced decreases in

246 liver glutathione concentration and content were independent of the initial inflammatory

247 status of old rats.

248 In agreement with our previous characterization of a cohort of old rats regarding their

249 inflammatory status (Mayot et al., 2007), rats belonging to the non-inflamed groups NI-Con

250 and NI-Str were clearly non-inflamed and those belonging to the inflamed groups LGI-Con

251 and LGI-Str exhibited low-grade inflammation at the beginning of the experiment. Indeed for

252 the formers, their initial plasma $\alpha_{2}$-macroglobulin and fibrinogen levels did not differ from

253 mean values previously observed for each corresponding first quartile in old rats or for adult

254 rats (8 months). Conversely, the others groups exhibited $\alpha_{2}$-macroglobulin and fibrinogen

255 levels similar to mean values previously observed in third quartiles in old rats. Of note, these

256 concentrations reflect low-grade inflammation since they are much lower than those reported

257 in acute (Breuillé et al., 1998; Breuillé et al., 1999) and chronic (Mercier et al., 2002)

258 inflammation. In addition, initial plasma concentrations of acute phase proteins in inflamed

259 old rats are consistent with those observed with age in human. Indeed, in old (66-76 years)

260 healthy subjects fibrinogen level was $\sim 47 \%$ greater and albumin level $\sim 12 \%$ lower than in

261 young (22-26 years) healthy subjects (El Yousfi et al., 2005). We have recently shown that

262 increased fibrinogen and $\alpha_{2}$-macroglobulin levels to the range observed in present inflamed

263 rats were associated with increased levels of soluble TNF- $\alpha$ receptor-1 (Mayot et al., 2007).

264 An activation of the TNF- $\alpha$ signaling is likely to occur in inflamed rats and might be active on

265 skeletal muscle protein metabolism, as recently suggested in human (Toth et al., 2005).

Interestingly, old rats submitted to the control treatment (I-Con and LGI-Con

267 groups) exhibited stable levels of plasma acute phase protein concentrations over time. Thus, 
268 the inflammatory status defined at the beginning of the experiment was maintained all along

269 the experiment in non-stressed rats. In parallel, final relative weights of liver, kidney and

270 spleen were higher in inflamed than non-inflamed old rats submitted to control treatment.

271 These organs play key role in the control of inflammation and immunity. Taken together, our

272 results support the fact that the spontaneous low-grade inflammation observed in old rats is a

273 chronic inflammation, which could affect the immune system and potentially weaken old rats.

274 This is further supported by the observation that body weight loss observed after the stress

275 was higher in inflamed than non-inflamed old rats.

276 In this context, the response of skeletal muscle to the stress regarding its mass and

277 protein turnover was interesting to compare between initially inflamed and non-inflamed old

278 rats. We recently showed that low-grade inflammation did not aggravate sarcopenia in control

279 conditions (Mayot et al., 2006). In the present study, we confirmed our precedent results since

280 skeletal muscle masses and protein turnover rates were not different between the two control

281 groups $\underline{\text { NI-Con }}$ and LGI-Con. Moreover, present results are going one step further, showing

282 that age-associated low-grade inflammation does not induce any negative effect in regards to

283 skeletal muscle mass and protein metabolism in case of additional stress.

284 The stress applied to old rats, consisting in a single endotoxin injection followed by a

285 23-day period of protein-energy malnutrition, induced severe metabolic disturbances

286 leading to increased mortality rate, loss of body weight and decreased abdominal organ

287 weights. The effect of the stress on acute phase protein response was protein-dependent.

288 Indeed, plasma levels of $\alpha_{2}$-macroglobulin increased, whereas fibrinogen levels decreased

289 and albumin levels did not change in stressed old rats. The increase in $\alpha_{2}$-macroglobulin is

290 consistent with the fact that sepsis and protein-deficient diet are known to stimulate its

291 synthesis in young rats (Breuillé et al., 1998; Lyoumi et al., 1998; Breuillé et al., 1999). If

292 the stress would have been only an inflammatory stress, an increase in fibrinogen would 
have been also expected. The fact that its plasma concentration decreased under the stress

294 suggests that either its utilization increased or its synthesis was limited by the malnutrition

295 in these old rats. The decrease in fibrinogen concentration is in agreement with data

296 obtained in piglets that were fed with a protein-deficient diet (Jahoor et al., 1999). Taken

297 together, these observations suggest that the transient inflammatory stress (i.e. endotoxin

298 injection) and the following protein-energy malnutrition stress used in the present study in

299 old rats may have had opposite effects on some metabolic aspects. Albumin levels were not

300 affected by the stress applied to old rats. By contrast, sepsis and protein-deficient diet are

301 known to decrease it in young rats (Lyoumi et al., 1998; Ruot et al., 2002). Thus, as we

302 already suggested (Mayot et al., 2007), albumin may not be a good nutritional marker in old

303 rats. Glutathione which is known to be very sensitive to protein intake (Hum et al., 1992)

304 and to decrease during infection (Breuillé et al., 1994) was highly depleted in the stressed

305 old rats. The overall effect of the present stress applied in old rats on plasma levels of acute

306 phase proteins and liver glutathione status was largely consistent with known effects of

307 protein-deficient nutrition in young animals, albumin excepted.

308 Unfortunately, the effect of low-grade inflammation on stress-induced mortality in old

309 rats could not be statistically analyzed because of too low number of animals. Low-grade

310 inflammation increased the susceptibility of old rats to body weight loss. Indeed, low-grade

311 inflamed rats lost almost $30 \mathrm{~g}$ more body weight under the stress than non-inflamed rats. The

312 higher stress-induced body weight loss in inflamed vs. non-inflamed rats could not be

313 explained by differences in adipose tissue or skeletal muscle weights. Part of the higher body

314 weight loss can be explained by higher decreases in liver, spleen kidneys and colon weights,

315 (Table 3). However, the results obtained from longitudinal observations (i.e. body weights

316 measured in the same rats before and during the treatment) are difficult to explain by the

317 transversal observations concerning mean skeletal muscles and organs weights from different 
318 groups of rats. Indeed, transversal observations are generally associated with higher

319 variability than measurements performed in longitudinal observations. Finally, tissues and organs that have not been dissected such as the skin, whose weight contributes to $\sim 20 \%$ of body weight (Obled and Arnal, 1992), might have been more affected in inflamed than noninflamed old rats.

Regarding the acute phase reaction, the stress applied in old rats modified differently

324 the fibrinogen kinetic in inflamed as compared to non-inflamed rats. The fibrinogen

325 concentration was decreased by the stress in both groups, but to a greater extend in inflamed than non-inflamed rats. The stress-induced increase in $\alpha_{2}$-macroglobulin might also have been higher but variability was too high to observe a significant effect in LGI-Str group. Finally, the inflammatory status of the old rats did not impact the stress response regarding the glutathione status and the skeletal muscle protein turnover. Taken together, the initial

330 inflammatory status of old rats did not have a strong impact on the metabolic response to the 331 present stress and for sure did not enhance the stress-induced skeletal muscle loss.

332 The failure of low-grade inflammation to worsen the stress-induced skeletal muscle 333 loss extends our previous observation made in non-stressed rats showing that low-grade 334 inflammation does not aggravate sarcopenia (Mayot et al., 2006). The present stress applied in 335 old rats had more effects on splanchnic organs than on skeletal muscles. This is consistent 336 with decreases observed in splanchnic organ weights but not in skeletal muscle weights after a $33750 \%$ dietary restriction in old rats (Chambon-Savanovitch et al., 1999). Similarly, higher 338 decreases in liver (49\%) than in gastrocnemius (25\%) weights were observed after 10 days of 339 starvation in old rats (Mosoni et al., 1999). Since muscle wasting and weakness are late 340 symptoms of malnutrition (Seiler, 2001), a longer malnutrition period might be required to

341 see differential reduction of skeletal muscle weight according to the initial inflammatory 342 status. In young rats, when starvation is initiated, there is a period of "saving" before skeletal 
343 muscle loss becomes significant (Chérel et al., 1991). However, there is a large decrease in

344 skeletal muscle protein synthesis observed in fasting young rats, even during the early phase

345 during which muscle weight is preserved. A decrease in skeletal muscle protein synthesis is

346 also observed in piglets fed a protein-deficient diet (Jahoor et al., 1999). In contrast, skeletal

347 muscle protein turnover was not affected in our stressed old rats. Taken together, these

348 observations suggest that the present double stress (endotoxin injection combined with

349 protein-energy malnutrition) might have induced some early metabolic effects that might have

350 been counteracted by the 23-day period of malnutrition. This assumption seems to be

351 emphasized by the observation of the decreased fibrinogen concentration under the stress, as

352 opposed to the increase usually observed after an inflammatory stress. Thus, to definitively

353 conclude that low-grade inflammation does not worsen sarcopenia in aged, it would be

354 probably necessary to test the impact of another type of stress, for example a stress inducing a

355 more marked skeletal muscle loss than the present stress or a stress for which no opposite

356 metabolic effects are observed.

357 In conclusion, the present study clearly indicates that low-grade inflammation

358 increases the body weight loss induced by the endotoxin injection followed by malnutrition, a

359 stress that mimics a transient febrile episode followed by a period of protein-energy

360 malnutrition, which frequently occurs in elderly. Stress-induced decreases in organ weights

361 and fibrinogen plasma concentration were enhanced by the initial low-grade inflammatory

362 status. The response of skeletal muscle (weight and protein turnover) was not worsened by the

363 low-grade inflammation. This extends and supports our previous findings that age-associated

364 low-grade inflammation does not aggravate sarcopenia. 


\section{Acknowledgements}

The authors thank Fabienne Béchereau, Philippe Denis, Johan Gimonet and Françoise Glomot for their technical participation.

\section{References}

Bales, C.W., Ritchie, C.S., 2002. Sarcopenia, weight loss, and nutritional frailty in the elderly. Annual Review of Nutrition 22, 309-323.

Barbieri, M., Ferrucci, L., Ragno, E., Corsi, A., Bandinelli, S., Bonafé, M., Olivieri, F., Giovagnetti, S., Franceschi, C., Guralnik, J.M., Paolisso, G., 2003. Chronic inflammation and the effect of IGF-I on muscle strength and power in older persons. American Journal of Physiology Endocrinology and Metabolism 284, E481-E487.

Bartali, B., Frongillo, E.A., Bandinelli, S., Lauretani, F., Semba, R.D., Fried, L.P., Ferrucci, L., 2006. Low nutrient intake is an essential component of frailty in older persons. Journals of Gerontology Series A-Biological Sciences \& Medical Sciences 61, 589593.

Breuillé, D., Voisin, L., Contrepois, M., Arnal, M., Obled, C., 1999. A sustained rat model for studying long-lasting catabolic state of sepsis. Infection and Immunity 67, 1079-1085.

Breuillé, D., Arnal, M., Rambourdin, F., Bayle, G., Levieux, D., Obled, C., 1998. Sustained modifications of protein metabolism in various tissues in a rat model of long-lasting sepsis. Clinical Science 94, 413-423.

Breuillé, D., Malmezat, T., Rosé, F., Pouyet, C., Obled, C., 1994. Assessment of tissue glutathione status during experimental sepsis. $16^{\text {th }}$ Congress of the European Society of Parenteral and Enteral Nutrition, Birmingham, Clinical Nutrition 13, p. 5-6.

Castaneda, C., Charnley, J.M., Evans, W.J., Crim, M.C., 1995. Elderly women accommodate to a low-protein diet with losses of body cell mass, muscle function, and immune 
response. American Journal of Clinical Nutrition 62, 30-39.

391 Chambon-Savanovitch, C., Felgines, C., Farges, M.C., Pernet, P., Cezard, J.P., Raul, F.,

392 Cynober, L., Vasson, M.P., 1999. Severe dietary restriction initiated in aged rats:

393 evidence for poor adaptation in terms of protein metabolism and intestinal functions.

394 European Journal of Clinical Investigation 29, 504-511.

395 Chérel, Y., Attaix, D., Rosolokska-Huszcz, D., Belkhou, R., Robin, J.P., Arnal, M., Le Maho,

396 Y., 1991. Whole-body and tissue protein synthesis during brief and prolonged fasting

397 in the rat. Clinical Science 81, 611-619.

398 Cohen, H.J., Harris, T., Pieper, C.F., 2003. Coagulation and activation of inflammatory 399 pathways in the development of functional decline and mortality in the elderly. American Journal of Medicine 114, 180-187.

Combaret, L., Béchet, D., Claustre, A., Taillandier, D., Richard, I., Attaix, D., 2003. Downregulation of genes in the lysosomal and ubiquitin-proteasome proteolytic pathways in calpain-3-deficient muscle. International Journal of Biochemistry \& Cell Biology 35, 676-684.

Cosqueric, G., Sebag, A., Ducolombier, C., Thomas, C., Piette, F., Weill-Engerer, S., 2006. Sarcopenia is predictive of nosocomial infection in care of the elderly. British Journal of Nutrition 96, 895-901.

De Martinis, M., Franceschi, C., Monti, D., Ginaldi, L., 2006. Inflammation markers predicting frailty and mortality in the elderly. Experimental and Molecular Pathology $80,219-227$.

El Yousfi, M., Mercier, S., Breuillé, D., Denis, P., Papet, I., Patureau Mirand, P., Obled, C., 2005. The inflammatory response to vaccination is altered in the elderly. Mechanisms of Ageing and Development 126, 874-881.

414 Ferrucci, L., Ble, A., Bandinelli, S., Windham, B.G., Simonsick, E.M., 2005. Inflammation: 
the fire of frailty? In: Carey, R. (Ed.), Longevity and Frailty. Springer-Verlag, Heidelberg, pp. 91-98.

417 Ferrucci, L., Harris, T.B., Guralnik, J.M., Tracy, R.P., Corti, M.C., Cohen, H.J., Penninx, B.,

418

419 Pahor, M., Wallace, R., Havlik, R.J., 1999. Serum IL-6 level and the development of disability in older persons. Journal of the American Geriatrics Society 47, 639-46.

Ferrucci, L., Penninx, B.W., Volpato, S., Harris, T.B., Bandeen-Roche, K., Balfour, J., Leveille, S.G., Fried, L.P., Md, J.M., 2002. Change in muscle strength explains accelerated decline of physical function in older women with high interleukin- 6 serum levels. Journal of American Geriatrics Society 50, 1947-1954.

Fried, L.P., Tangen, C.M., Walston, J., Newman, A.B., Hirsch, C., Gottdiener, J., Seeman, T., Tracy, R., Kop, W.J., Burke, G., McBurnie, M.A., 2001. Frailty in older adults: evidence for a phenotype. Journals of Gerontology Series A-Biological Sciences \& Medical Sciences 56, M146-M156.

Fried, L.P., Walston, J., 2003. Frailty and failure to thrive. In: Hazzard, W., Blass, J.P., Halter, J.B., Ouslander, J., Tinetti, M. (Eds.), Principles of Geriatric Medicine and Gerontology. New York: McGraw-Hill, pp. 1487-1502.

Greiwe, J.S., Cheng, B., Rubin, D.C., Yarasheski, K.E., Semenkovich, C.F., 2001. Resistance exercise decreases skeletal muscle tumor necrosis factor alpha in frail elderly humans. FASEB Journal 15, 475-482.

Harris, T.B., Ferrucci, L., Tracy, R.P., Corti, M.C., Wacholder, S., Ettinger, W.H. Jr, Heimovitz, H., Cohen, H.J., Wallace, R., 1999. Associations of elevated interleukin-6 and C-reactive protein levels with mortality in the elderly. American Journal of Medicine 106, 506-512.

Heymsfield, S.B., McManus, C., Stevens, V., Smith, J., 1982. Muscle mass: reliable indicator of protein-energy malnutrition severity and outcome. American Journal of Clinical 
Nutrition 35, 1192-1199.

441 Hum, S., Koski, K.G., Hoffer, L.J., 1992. Varied protein intake alters glutathione metabolism 442 in rats. Journal of Nutrition 122, 2010-2018.

443 Jahoor, F., Wykes, L., Del Rosario, M., Frazer, M., Reeds, P.J., 1999. Chronic protein 444 undernutrition and an acute inflammatory stimulus elicit different protein kinetic responses in plasma but not in muscle of piglets. Journal of Nutrition 129, 693-699.

Lyoumi, S., Tamion, F., Petit, J., Déchelotte, P., Dauguet, C., Scotté, M., Hiron, M., Leplingard, A., Salier, J.P., Daveau, M., Lebreton, J.P., 1998. Induction and modulation of acute-phase response by protein malnutrition in rats: comparative effect

Malmezat, T., Breuillé, D., Pouyet, C., Patureau Mirand, P., Obled, C., 1998. Metabolism of cysteine is modified during the acute phase of sepsis in rats. Journal of Nutrition 128,

Mayot, G., Breuillé, D., Obled, C., Papet, I., 2006. Muscle mass and protein synthesis are not $97-105$. modified by low grade inflammation in old rats. $28^{\text {th }}$ Congress of the European Society of Parenteral and Enteral Nutrition, Istanbul, p. 171.

Mayot, G., Vidal, K., Martin, J.-F., Breuillé, D., Blum, S., Obled, C., Papet, I., 2007. Prognostic values of [alpha]2-macroglobulin, fibrinogen and albumin in regards to mortality and frailty in old rats. Experimental Gerontology 42, 498-505.

Mercier, S., Breuillé, D., Mosoni, L., Obled, C., Patureau Mirand, P., 2002. Chronic 461 inflammation alters protein metabolism in several organs of adult rats. Journal of Nutrition 132, 1921-1928.

Mosoni, L., Malmezat, T., Valluy, M.C., Houlier, M.L., Attaix, D., Mirand, P.P., 1999. Lower 
protein synthesis. American Journal of Physiology 277, E608-616.

466

467

468

469

470

471

472

473

474

475

476

477

478

479

480

481

482

483

484

Mühlberg, W., Sieber, C., 2004. Sarcopenia and frailty in geriatric patients: implications for training and prevention. Zeitschrift Fur Gerontologie Und Geriatrie 37, 2-8.

Obled, C., Arnal, M., 1992. Contribution of skin to whole-body protein synthesis in rats at different stages of maturity. Journal of Nutrition 122, 2167-2173.

Obled, C., Papet, I., Breuillé, D., 2002. Metabolic bases of amino acid requirements in acute diseases. Current Opinion in Clinical Nutrition and Metabolic Care 5, 189-197.

Paganelli, R., Di Iorio, A., Cherubini, A., Lauretani, F., Mussi, C., Volpato, S., Abate, M., Abate, G., Ferrucci, L., 2006. Frailty of older age: the role of the endocrine--immune interaction. Current Pharmaceutical Design 12, 3147-3159.

Puts, M.T.E., Visser, M., Twisk, J.W.R., Deeg, D.J.H., Lips, P., 2005. Endocrine and inflammatory markers as predictors of frailty. Clinical Endocrinology 63, 403-411.

Ruot, B., Béchereau-Rambourdin, F., Bayle, G. , Breuillé, D., Obled, C., 2002. The response of liver albumin synthesis to infection in rats varies with the phase of the inflammatory process. Clinical Science 102, 107-114.

Seiler, W.O., 2001. Clinical pictures of malnutrition in ill elderly subjects. Nutrition 17, 496498.

Toth, M.J., Matthews, D.E., Tracy, R.P., Previs, M.J., 2005. Age-related differences in skeletal muscle protein synthesis: relation to markers of immune activation. American Journal of Physiology-Endocrinology and Metabolism 288, E883-E891.

Vanitallie, T.B., 2003. Frailty in the elderly: contributions of sarcopenia and visceral protein depletion. Metabolism 52, 22-26.

Vellas, B.J., Albarede, J.L., Garry, P.J., 1992. Diseases and aging: patterns of morbidity with age; relationship between aging and age-associated diseases. American Journal of Clinical Nutrition 55, 1225S-1230S. 
490 Walston, J., McBurnie, M.A., Newman, A., Tracy, R.P., Kop, W.J., Hirsch, C.H., Gottdiener, J., Fried, L.P., 2002. Frailty and activation of the Inflammation and coagulation systems with and without clinical comorbidities - results from the cardiovascular health study. Archives of Internal Medicine 162, 2333-2341. 


\section{$494 \quad$ Figure legends}

495

496 FIGURE 1 Time-course of cumulative relative body weight changes in non-inflamed and low-grade inflamed old rats submitted to the control or the stress treatment.

498 Means \pm SE $(n=5$ or 7$)$. There are significant effects of the stress and the time on body 499 weight changes and significant interactions between the stress and the time, between the 500 initial inflammatory status and the time, and between the stress, the initial inflammatory status 501 and the time (ANOVA for repeated measurements with the stress and the initial inflammatory 502 status as the between-rat factors and the time as the within-rat factor). NI-Con: non-inflamed 503 rats submitted to the control treatment, NI-Str: non-inflamed rat submitted to the stress 504 treatment, LGI-Con: inflamed rats submitted to the control treatment, LGI-Str: inflamed rats 505 submitted to the stress treatment.

507 FIGURE 2 Skeletal muscle protein turnover in non-inflamed and low-grade inflamed old rats

508 submitted to the control or the stress treatment.

509 Means \pm SE ( $=5$ or 7$)$. Two-way (initial inflammatory status and treatment) ANOVA:

510 epitrochlearis protein synthesis and protein degradation: none significant effect, $P<0.05$, NI-

511 Con: non-inflamed rats submitted to the control treatment, NI-Str: non-inflamed rat submitted

512 to the stress treatment, LGI-Con: inflamed rats submitted to the control treatment, LGI-Str:

513 inflamed rats submitted to the stress treatment.

515 FIGURE 3 Time-course of plasma $\alpha_{2}$-macroglobulin, fibrinogen and albumin concentrations 516 in non-inflamed and low-grade inflamed old rats receiving the control or the stress treatment.

517 Bars represent means and SE for 5 or 7 rats in each group at each time. $\alpha_{2}$-macroglobulin:

518 significant effects of the stress, the initial inflammatory status and the time, (interaction 
519 between the stress and the time $P=0.056$ ); fibrinogen: significant effects of the stress, the

520 initial inflammatory status and the time, significant interaction between the stress and the time

521 (interaction between the stress, the initial inflammatory status and the time $P=0.072$ );

522 albumin: significant effect of the initial inflammatory status (ANOVA for repeated

523 measurements with the stress and the initial inflammatory status as the between-rat factors

524 and the time as the within-rat factor). Within a group, bars not sharing a common letter are

525 different (ANOVA for repeated measurement, followed by Fisher's PLSD test). NI-Con: non-

526 inflamed rats submitted to the control treatment, NI-Str: non-inflamed rat submitted to the

527 stress treatment, LGI-Con: inflamed rats submitted to the control treatment, LGI-Str: inflamed

528 rats submitted to the stress treatment.

529

530 FIGURE 4 Liver glutathione status in non-inflamed and low-grade inflamed old rats

531 submitted to the control or the stress treatment.

532 Means \pm SE ( $n=5$ or 7$)$. Two-way (initial inflammatory status and treatment) ANOVA:

533 significant effect of the treatment for both concentration and content, $P<0.05$, NI-Con: non-

534 inflamed rats submitted to the control treatment, NI-Str: non-inflamed rat submitted to the 535 stress treatment, LGI-Con: inflamed rats submitted to the control treatment, LGI-Str: inflamed 536 rats submitted to the stress treatment. 
Table 1

Old rats' characteristics before the experimental period

\begin{tabular}{|c|c|c|c|c|c|}
\hline Initial inflammatory status & Non-inflamed & & $\underline{\text { Low-grade infla }}$ & & \\
\hline Treatment & Control & Stress & Control & Stress & \\
\hline Groups & $\underline{\text { NI-Con }}$ & $\underline{\text { NI-Str }}$ & LGI-Con & LGI-Str & \\
\hline$\alpha_{2}$-macroglobulin at D-7(mg/l) & $36 \pm 4$ & $40 \pm 12$ & $167 \pm 37$ & $133 \pm 26$ & $\mathrm{I}$ \\
\hline Fibrinogen at D-7 (g/l) & $3.24 \pm 0.18$ & $3.12 \pm 0.22$ & $4.42 \pm 0.39$ & $4.51 \pm 0.28$ & I \\
\hline Albumin at D-7 (g/l) & $14.6 \pm 0.9$ & $13.3 \pm 0.7$ & $12.2 \pm 0.8$ & $12.1 \pm 1.0$ & $\mathrm{I}(P=0.066)$ \\
\hline Body weight at D-22 (g) & $693 \pm 68$ & $627 \pm 24$ & $613 \pm 33$ & $704 \pm 45$ & ns \\
\hline Food intake before D0 $(\mathrm{g} / \mathrm{d})$ & $22.0 \pm 1.4$ & $21.1 \pm 1.2$ & $21.3 \pm 0.9$ & $22.1 \pm 0.7$ & ns \\
\hline
\end{tabular}

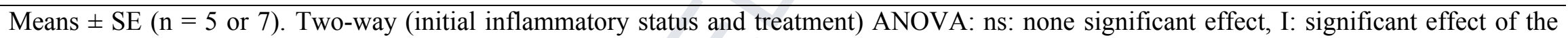

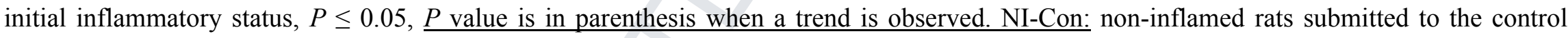


treatment, NI-Str: non-inflamed rat submitted to the stress treatment, LGI-Con: low-grade inflamed rats submitted to the control treatment, $\underline{\text { LGI- }}$

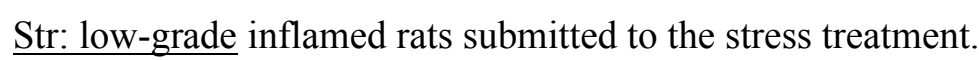


Table 2

Skeletal muscle weights in non-inflamed and low-grade inflamed old rats submitted to the control or the stress treatment.

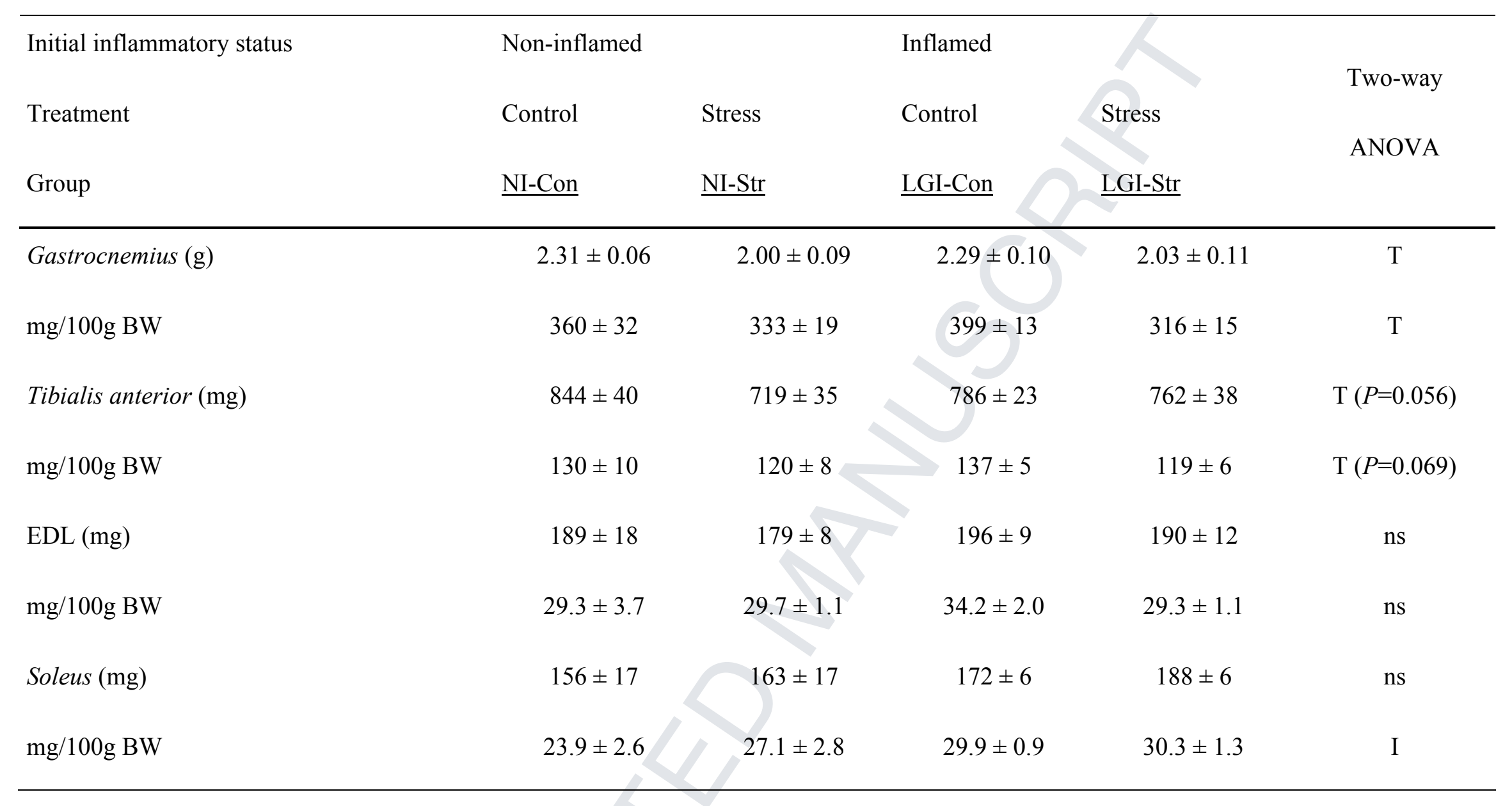


Means \pm SE ( $\mathrm{n}=5$ or 7$)$. Two-way (initial inflammatory status and treatment) ANOVA: ns: none significant effect, I: significant effect of the

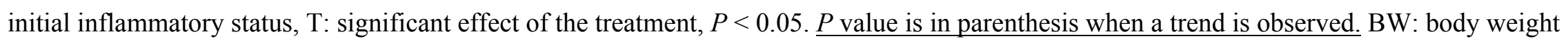

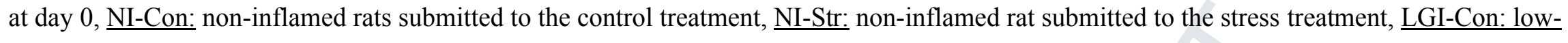
grade inflamed rats submitted to the control treatment, LGI-Str: low-grade inflamed rats submitted to the stress treatment. 
Table 3

Organ and adipose tissue weights in non-inflamed and low-grade inflamed old rats submitted to the control or the stress treatment.

\begin{tabular}{|c|c|c|c|c|c|}
\hline \multirow{3}{*}{$\begin{array}{l}\text { Initial inflammatory status } \\
\text { Treatment } \\
\text { Group }\end{array}$} & \multicolumn{2}{|c|}{ Non-inflamed } & \multicolumn{2}{|c|}{ Inflamed } & \multirow{3}{*}{$\begin{array}{l}\text { Two-way } \\
\text { ANOVA }\end{array}$} \\
\hline & Control & Stress & Control & Stress & \\
\hline & $\underline{\text { NI-Con }}$ & $\underline{\text { NI-Str }}$ & $\underline{\text { LGI-Con }}$ & $\underline{\text { LGI-Str }}$ & \\
\hline Liver (g) & $15.9 \pm 1.3$ & $11.8 \pm 0.5$ & $17.7 \pm 1.3$ & $12.5 \pm 0.4$ & $\mathrm{~T}$ \\
\hline $\mathrm{g} / 100 \mathrm{~g} \mathrm{BW}$ & $2.41 \pm 0.08^{\mathrm{a}}$ & $1.96 \pm 0.02^{b}$ & $3.06 \pm 0.17^{\mathrm{c}}$ & $1.96 \pm 0.09^{b}$ & T, I, TxI \\
\hline Kidneys (g) & $3.55 \pm 0.17^{\mathrm{ab}}$ & $2.89 \pm 0.14^{\mathrm{a}}$ & $5.66 \pm 0.40^{c}$ & $3.82 \pm 0.25^{b}$ & T, I, TxI \\
\hline $\mathrm{mg} / 100 \mathrm{~g} \mathrm{BW}$ & $548 \pm 040^{\mathrm{a}}$ & $480 \pm 19^{a}$ & $986 \pm 71^{b}$ & $601 \pm 50^{\mathrm{a}}$ & T, I, TxI \\
\hline Small Intestine (g) & $10.4 \pm 0.5$ & $8.5 \pm 0.5$ & $10.2 \pm 0.3$ & $9.7 \pm 0.4$ & $\mathrm{~T}$ \\
\hline $\mathrm{g} / 100 \mathrm{~g} \mathrm{BW}$ & $1.60 \pm 0.10$ & $1.42 \pm 0.03$ & $1.78 \pm 0.06$ & $1.53 \pm 0.11$ & $\mathrm{~T}$ \\
\hline
\end{tabular}




$\begin{array}{lccccc}\text { Colon }(\mathrm{g}) & 1.80 \pm 0.10 & 1.78 \pm 0.06 & 1.99 \pm 0.22 & 1.67 \pm 0.10 & \mathrm{~ns} \\ \mathrm{mg} / 100 \mathrm{~g} \mathrm{BW} & 279 \pm 26 & 297 \pm 16 & 344 \pm 31 & 267 \pm 28 & \mathrm{TxI}(P=0.098) \\ \text { Mesentery (g) } & 7.36 \pm 2.70 & 4.28 \pm 0.87 & 6.78 \pm 1.34 & 5.05 \pm 1.28 & \mathrm{~ns} \\ \mathrm{~g} / 100 \mathrm{~g} \mathrm{BW} & 1.07 \pm 0.34 & 0.71 \pm 0.14 & 1.18 \pm 0.23 & 0.74 \pm 0.17 & \mathrm{~T}(P=0.091) \\ \text { Epidydimal adipose tissue (g) } & 12.1 \pm 2.8 & 9.5 \pm 2.1 & 9.1 \pm 0.5 & 9.1 \pm 1.3 & \mathrm{~ns} \\ \text { g/100g BW } & 1.77 \pm 0.33 & 1.55 \pm 0.32 & 1.58 \pm 0.08 & 1.36 \pm 0.17 & \mathrm{~ns}\end{array}$

Means \pm SE $(n=5$ or 7$)$. Two-way (initial inflammatory status and treatment) ANOVA: ns: none significant effect, I: significant effect of the initial inflammatory status, T: significant effect of the treatment, TxI: significant interaction between the two factors, $P<0.05 . \underline{P \text { value is in }}$ parenthesis when a trend is observed. ${ }^{a, b, c}$ : values, within a row, not sharing a common letter are significantly different (Fisher's test). BW: body weight at day 0, NI-Con: non-inflamed rats submitted to the control treatment, NI-Str: non-inflamed rat submitted to the stress treatment, LGICon: low-grade inflamed rats submitted to the control treatment, LGI-Str: low-grade inflamed rats submitted to the stress treatment. 


\section{FIGURE 1}

Time (d)

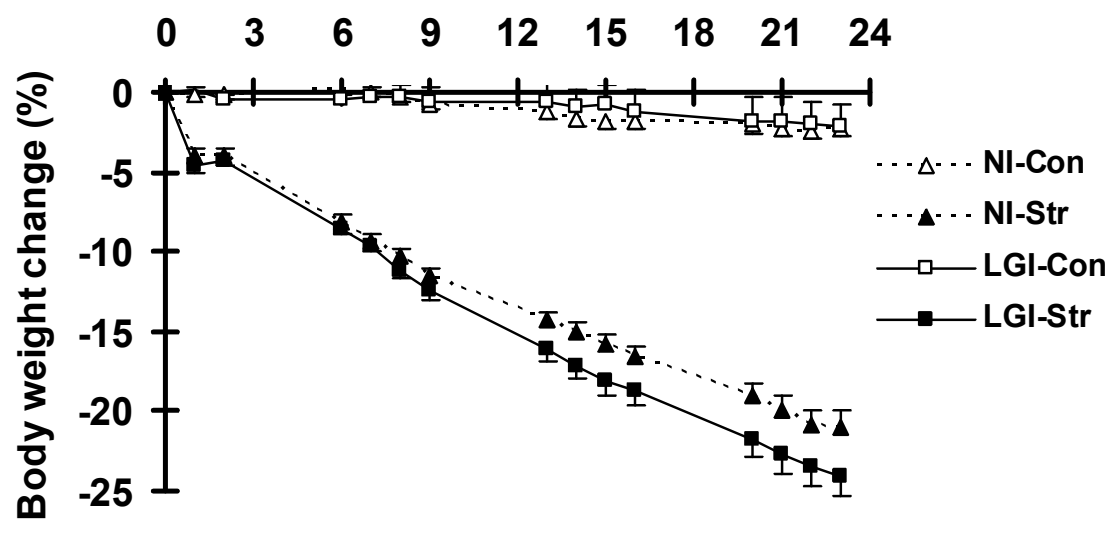


FIGURE 2

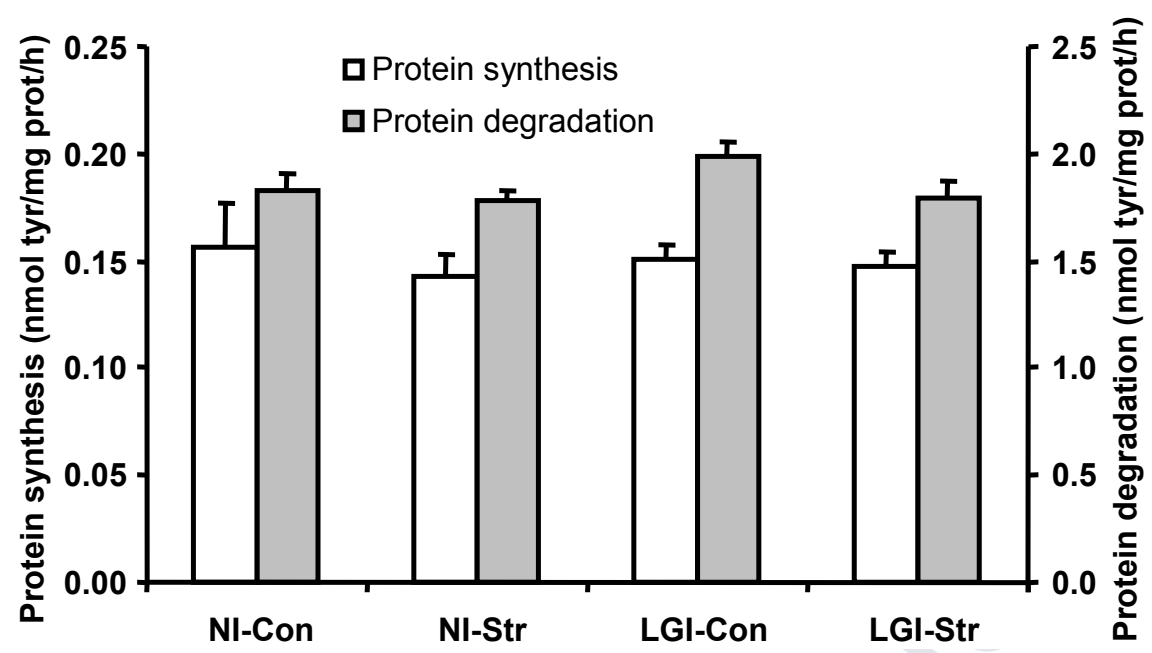


FIGURE 3
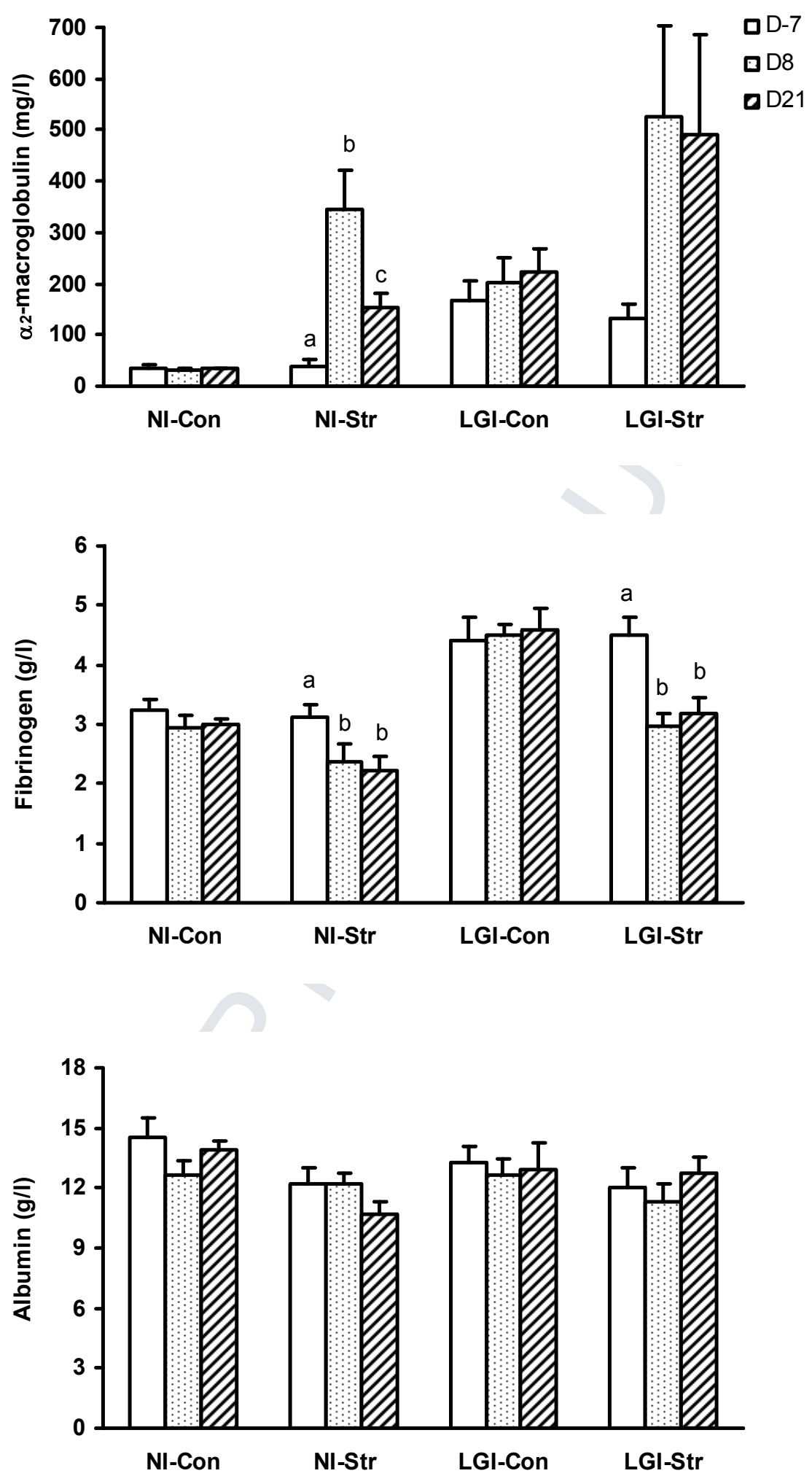
FIGURE 4

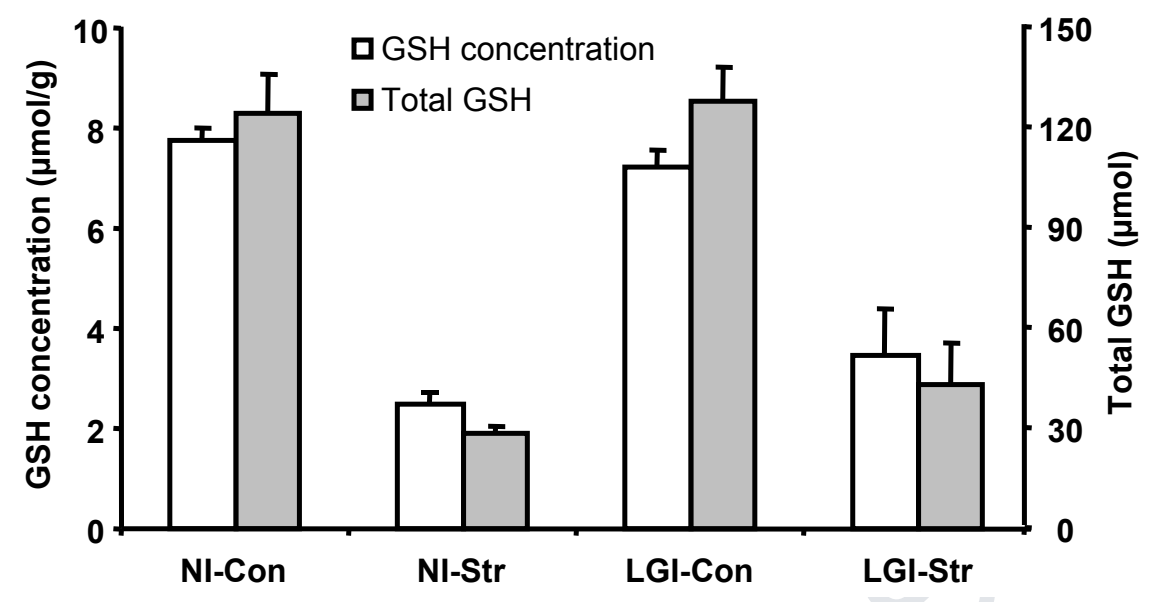

